\title{
Fator Cronológico na Credibilidade do Evolucionismo entre os Discentes da Universidade Severino Sombra
}

\author{
Maria das Graças Avila Guimarães \\ Universidade Severino Sombra, Centro de Ciências Exatas, \\ Tecnológicas e da Natureza \\ mgaguima@yahoo.com.br \\ Catia Maria Diogo \\ Universidade Severino Sombra, Centro de Ciências Exatas, \\ Tecnológicas e da Natureza \\ cmdiogo@oi.com.br \\ Francelle Piedade Avelar Silva \\ Universidade Severino Sombra, Centro de Ciências da Saúde \\ francelleavelarehotmail.com; \\ Ulisses Gonçalves Teixeira \\ Universidade Severino Sombra, Centro de Ciências da Saúde \\ ugteixeirehotmail.com \\ Renata Fraga Pinheiro \\ Universidade Severino Sombra, Centro de Ciências da Saúde \\ renatafragapinheiro@gmail.com \\ Marise Maleck de Oliveira Cabral \\ Laboratório de Insetos Vetores, Universidade Severino Sombra \\ Centro de Ciências Exatas, Tecnológicas e da Natureza \\ mmaleck@oi.com.br
}

\begin{abstract}
Resumo: Os conceitos evolucionistas começaram a se fundamentar a partir de Descartes, Buffon, Lamarck e Darwin e ao mesmo tempo despertaram as contradições das doutrinas criacionistas. A credibilidade do evolucionismo por faixa etária dos alunos de graduação da Universidade Severino Sombra (USS), nas diferentes áreas do saber foi o objeto deste trabalho. A população discente se concentrou na faixa etária entre 20 a 24 anos em que predomina o acreditar em ideias evolucionistas, não se podendo avaliar se estes posicionamentos independem da divulgação ou do ensino do criacionismo introduzido há algum tempo nas escolas públicas de alguns estados brasileiros. Pode-se inferir, a partir deste estudo, um grande desconhecimento sobre a teoria cientifica evolucionista entre os discentes dos cursos superiores pesquisados na USS.
\end{abstract}

Palavras-chave: Charles Darwin. Evolução. Educação. 


\title{
Students Chronologic Factor and Their Credibility on Evolutionism at Severino Sombra University
}

\begin{abstract}
Evolutionary concepts have begun to substantiate from Descartes, Buffon, Lamarck and Darwin, and while the contradictions aroused creationist doctrines. The credibility of evolution by age groups of undergraduate students at the University Severino Sombra (USS) in the different areas of knowledge, was the object of this work. The student population is concentrated in the age group between 20 to 24 years where the general belief in evolutionary ideas, unable to assess whether these positions are independent of disclosure or teaching of creationism introduced some time ago in public schools in some states. It can be inferred from this study is widespread ignorance about the scientific theory of evolution among students of degree courses surveyed in the USS.
\end{abstract}

Keywords: Charles Darwin. Evolution. Education.

\section{Introdução}

\begin{abstract}
"A evolução é uma teoria, um sistema ou uma hipótese? É muito mais do que isso. É uma condição geral à qual se devem dobrar todas as teorias, todas as hipóteses, todos os sistemas; uma condição a que devem satisfação doravante para que possam ser tomadas em consideração e para que possam ser certas" (Teilhard de Chardin, 1955, p. 148).
\end{abstract}

A história dos povos antigos, das mais remotas sociedades tribais às grandes civilizações antigas dos egípcios, babilônios, persas, gregos e romanos demonstra a preocupação com as questões das origens do mundo, dos seres vivos e do homem, questão tão antiga quanto a humanidade. Em suas tradições e sistemas de ideias e crenças tem em comum a procura, entre dois mundos opostos: o "mundo do sagrado" ou o "mundo profano", de resposta às questões que se levantam do mundo do real (Mircea, 1963; Caillois, 1963, 1972; Makarius, 1974; Girard, 1972, como citado por Pino, 2009, p. 4). Os mitos e as crenças constituem parte da história e das tradições dos povos, antigos e modernos (Pino, 2009). A ciência, considerada constituinte do mundo profano, em geral se opõe aos dogmas, pela utilização de um método de investigação criado no iluminismo.

As ideias evolucionistas, consideradas como a espinha dorsal da Biologia atual, um paradigma para muitos, está baseada em uma ciência fundamentada numa teoria não comprovada, ainda discutida se seria uma ciência ou uma fé. Acreditar no evolucionismo ou na criação especial encontra adeptos que não foram capazes, até o presente, de provar suas crenças (L.H. Matthews, Introdução para a "The Origin of Species", de Charles Darwin, Dent and Sons, London, 1971, p. XI, como citado por Duane T. Gish, "Evolution: the Challenge of the Fossil Record, Creation-Life Publishers, El Cajon, 7a. ed. 1992, p. 15 como citado por Pinheiro, 2000, p.4). 
Ao longo da história da teoria da evolução após Darwin, tanto para a comunidade científica como para o público leigo, observa-se a dificuldade da recepção da seleção natural como mecanismo criador de diversidade no mundo natural. Essa dificuldade tem raízes de caráter metafísico, além do fundamento técnico de Darwin não dispor de uma teoria genética para fundamentar o processo de seleção e de acumulação de mudanças. A aceitação de um vasto processo de transformação orgânica foi relativamente rápida e definitiva entre os naturalistas europeus, após a publicação de Origem das espécies, embora isto não tenha ocorrido em relação ao mecanismo da seleção natural. Por outro lado, a aceitação da seleção natural como eliminadora das imperfeições de uma população foi imediata (Ferreira, 2007, p.105).

Johnson (1998, p.71 citado por Pinheiro, 2000, p.4) discute uma declaração de Richard Lewontin sobre "o darwinismo ser uma ideologia, um conjunto de idéias às quais a realidade deve se adaptar." Referindo-se ao posicionamento dos pesquisadores ele declarou:

\footnotetext{
Nós ficamos do lado da ciência, apesar do patente absurdo de algumas de suas construções..., apesar da tolerância da comunidade científica em prol de teorias certamente não comprovadas, porque nós temos um compromisso prévio, um compromisso com o materialismo... Somos forçados por nossa prévia adesão à concepção materialista do universo a criar um aparato de investigação e um conjunto de conceitos que produzam explicações materialistas, não importa quão contraditórias, quão enganosas e quão mitificadas para os não iniciados. Além disso, para nós o materialismo é absoluto, não podemos permitir que o "Pé Divino" entre por nossa porta.
}

"Especificamente no século XVIII, a história natural tratava da história de tudo aquilo que foi "naturalmente" criado por Deus: animais plantas, minerais e homens eram os objetos de descrição e também de classificação dos naturalistas". Nos séculos XVII e XVIII a história natural se baseava na organização da multiplicidade, no encantamento com a diversidade do mundo criado por Deus, fato também decorrente das grandes navegações e descoberta da diversidade dos outros continentes. O amadurecimento dos naturalistas levou-os da percepção do espetáculo da natureza até a busca da compreensão da engrenagem que colocava essa natureza em funcionamento. Observa-se ainda naquela época o florescimento da história natural, que, apoiada na filosofia mecanicista, aceitava um Deus criador, porém negava-lhe uma intervenção nas operações cotidianas do Universo. Por outro lado, ocorre um enfraquecimento da história natural em função da instauração de uma metodologia própria da filosofia mecanicista que revelava ser inadequada à interpretação do fenômeno da vida, especificamente a respeito da reprodução, do mecanismo e da produção de semelhantes (Castanheda, 1995, p. 34).

A mudança observada na mentalidade dos naturalistas e na maneira de elaborar teorias durante todo o século XVIII deveu-se ao prestígio da física newtoniana. O estudo dos seres vivos relacionados ao mecanicismo tornou-se um processo rico e intricado em suas implicações metodológicas. As inúmeras expedições de naturalistas europeus pelas regiões tropicais ao longo dos séculos XVIII e XIX levaram para o debate científico em história natural temas que correlacionavam os seres vivos com o clima, as características da distribuição geográfica dos animais e vegetais e muitos outros. A ciência europeia 
deslumbrou-se com a magnitude da diversidade de seres vivos então descritos pelos naturalistas, daí surgindo o grande desafio para a história natural, que deveria explicar e ordenar essa diversidade (Ferreira, 2007, p.3).

“À medida que foram ganhando corpo com Descartes, Buffon, Lamarck e Darwin os conceitos evolucionistas ganharam também contraditores nas doutrinas criacionistas, de enraizamento dualista, quase sempre ligada, no Ocidente, às religiões de origem cristã" (Maia, 2004, p.364). Ainda no século XXI, a discussão sobre evolução como contraposição ao criacionismo permanece, sendo considerada discussão de opostos entre ciência e religião, materialismo e religiosidade, ateísmo e crença em Deus.

Segundo Fedeli, Vanini, Vanini, Oliveira e Daniel (2003, p.5) curiosamente, hoje, o dogma da evolução é aceito por quase todos sem qualquer exame mais profundo. Entre os estudantes encontrou-se a aceitação de que o homem tem origem no macaco ou em um ancestral comum do macaco e do homem; no entanto, "ninguém se pergunta que animal irá ser gerado pelo homem no futuro".

Observada a predominância de faixas etárias dos discentes nos diferentes cursos de graduação, propõe-se, neste trabalho, a identificar a credibilidade do evolucionismo nos grupos cronológicos que se incluem no conhecer, analisar e divulgar as ideias e os conhecimentos evolucionistas que devem subsidiar as diferentes áreas do saber.

\section{Metodologia}

O projeto de pesquisa originou-se da proposta de participação nas comemorações dos duzentos anos de Charles Darwin (1809-1882) e dos cento e cinquenta anos da Teoria da Seleção Natural.

A Universidade Severino Sombra (USS), no segundo período letivo de 2009, apresentou à comunidade 33 cursos, entre graduação em nível superior e de tecnologia. Destes cursos, optou-se por trabalhar com 21, por serem aqueles que registravam matrícula no semestre em que a pesquisa foi realizada, nos horários em que havia o maior número de alunos matriculados. Foram alvos da pesquisa: oito cursos pertencentes ao Centro de Ciências da Saúde (CECS); oito, do Centro Ciências Sociais Aplicadas e Humanas (CECSAH) e cinco, do Centro de Ciências Exatas, Tecnológicas e da Natureza (CECETEN), entre os diurnos e noturnos. Foram entrevistados dez discentes de cada uma das turmas selecionadas aleatoriamente, conforme previsto no projeto inicial, apesar da dificuldade, pois em algumas turmas havia um número menor do que o previsto ou que se recusaram a participar.

Os questionários, contendo nove questões, foram entregues, pessoalmente, aos alunos de cada turma participante, por monitores do projeto. Participaram como monitores alunos de Biomedicina e de Ciências Biológicas, que naquele semestre cursavam a disciplina Evolução e, quando convidados, aceitaram inserir-se no projeto.

Para este trabalho optou-se por estudar apenas uma das questões cujo enfoque era acreditar em ideias evolucionistas, de acordo com as faixas etárias dos participantes, que foram usadas de acordo com as definidas pelo Instituto Brasileiro de Geografia e Estatística e para sua análise foram considerados os percentuais em relação ao número amostral. 
Fator Cronológico na Credibilidade do Evolucionismo entre os Discentes da Universidade Severino Sombra

Maria das Graças Avila Guimarães - Catia Maria Diogo - Francelle Piedade Avelar Silva - Ulisses Gonçalves Teixeira - Renata Fraga Pinheiro - Marise Maleck de Oliveira Cabral

\section{Resultados}

Comparando-se os resultados obtidos para a questão "acreditar em ideias evolucionistas", entre as grandes áreas do conhecimento humano, encontra-se predominância entre os estudantes na faixa etária entre 20 a 24 anos, $45,8 \%$ do total de participantes, posicionaremse com a resposta afirmativa, conforme demonstrado na Figura 1.

Para todas as faixas etárias disseram acreditar em ideias evolucionistas $75,4 \%$ entre os participantes da área da saúde, $76,8 \%$ de humanas e $78,0 \%$ de ciência, tecnologia e natureza. Registrou-se uma maior a adesão a ideias evolucionistas entre os alunos do CECETEN, apesar de não ser significativamente maior que entre os do CECS e do CECSAH.

No curso de Teologia, do total de alunos, $85,0 \%$ disseram acreditar em ideias evolucionistas; predominavam alunos com idade entre 60-69 anos, 67,0\%.

Entre os cursos participantes com maior número de alunos que não acreditavam em ideias evolucionistas encontrou-se Matemática, 50,0\%, com predominância de idade entre 25-29 anos; Odontologia, 50,0\%, com faixa etária predominante entre 20-24 anos e Pedagogia, $67,0 \%$, também com predominância da faixa etária entre 20-24 anos.

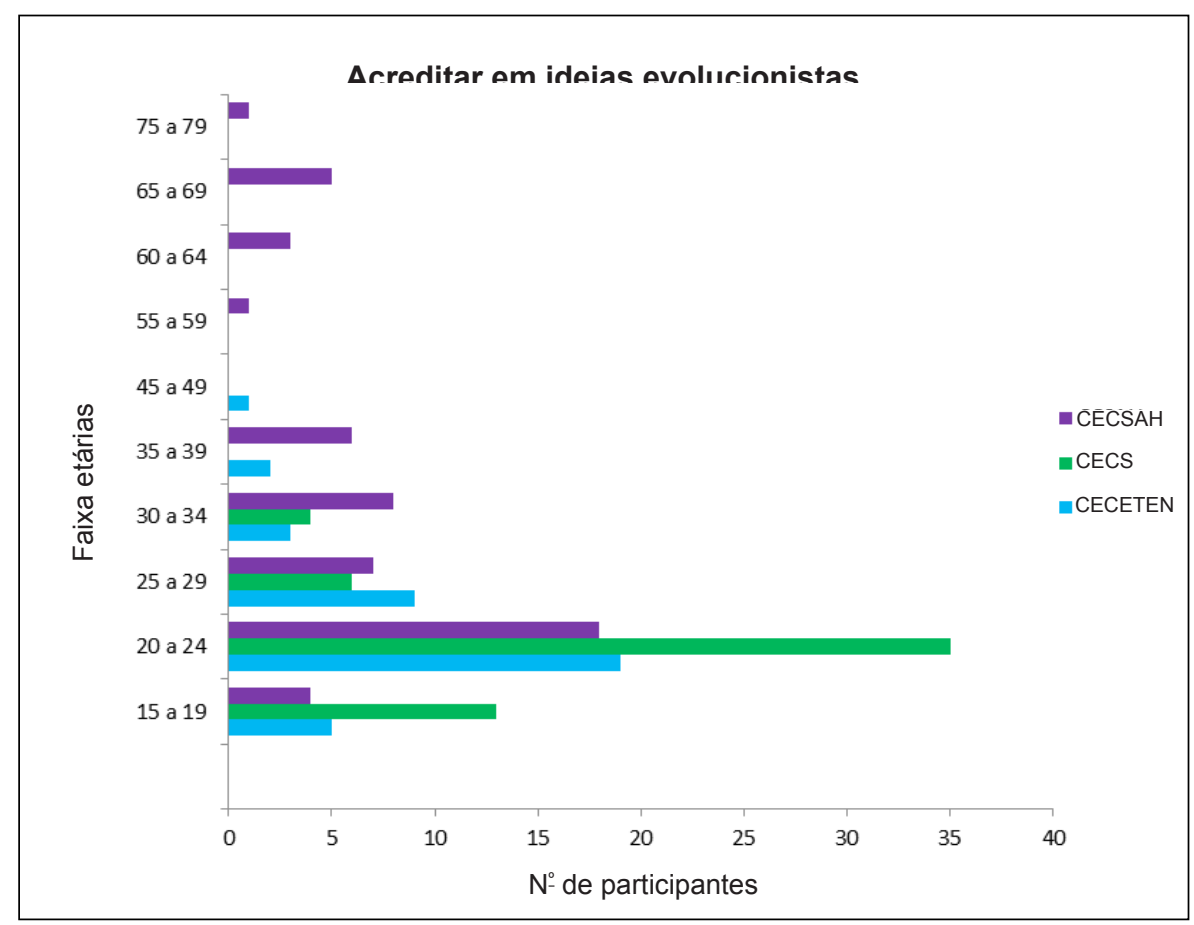

Figura 1. Número de estudantes, entre os entrevistados, por faixa etária, que acreditam em ideias evolucionistas, de acordo com Darwin, das diferentes áreas do conhecimento, da Universidade Severino Sombra

Considerados os cursos participantes dos diferentes Centros Acadêmicos das diferentes áreas do conhecimento, para o acreditar em ideias evolucionistas, encontra-se a ratificação de um maior percentual, para a mesma faixa etária, 20 a 24 anos, conforme demonstrado nas figuras 2,3 e 4 . 
Fator Cronológico na Credibilidade do Evolucionismo entre os Discentes da Universidade Severino Sombra

Maria das Graças Avila Guimarães - Catia Maria Diogo - Francelle Piedade Avelar Silva - Ulisses Gonçalves Teixeira - Renata Fraga Pinheiro - Marise Maleck de Oliveira Cabral

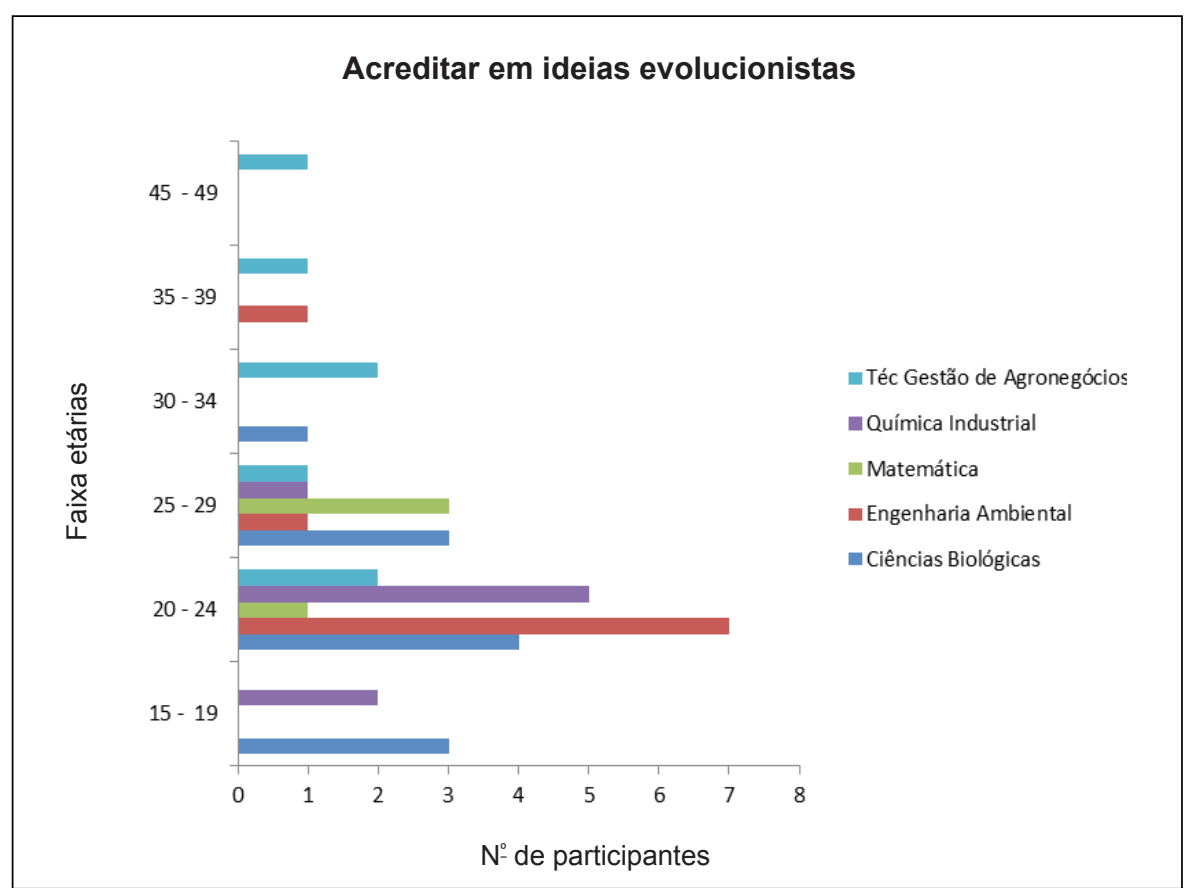

Figura 2. Número de estudantes, entre os entrevistados, por faixa etária, que acreditam em ideias evolucionistas, de acordo com Darwin, do Centro de Ciências Exatas, Tecnológicas e da Natureza, da Universidade Severino Sombra

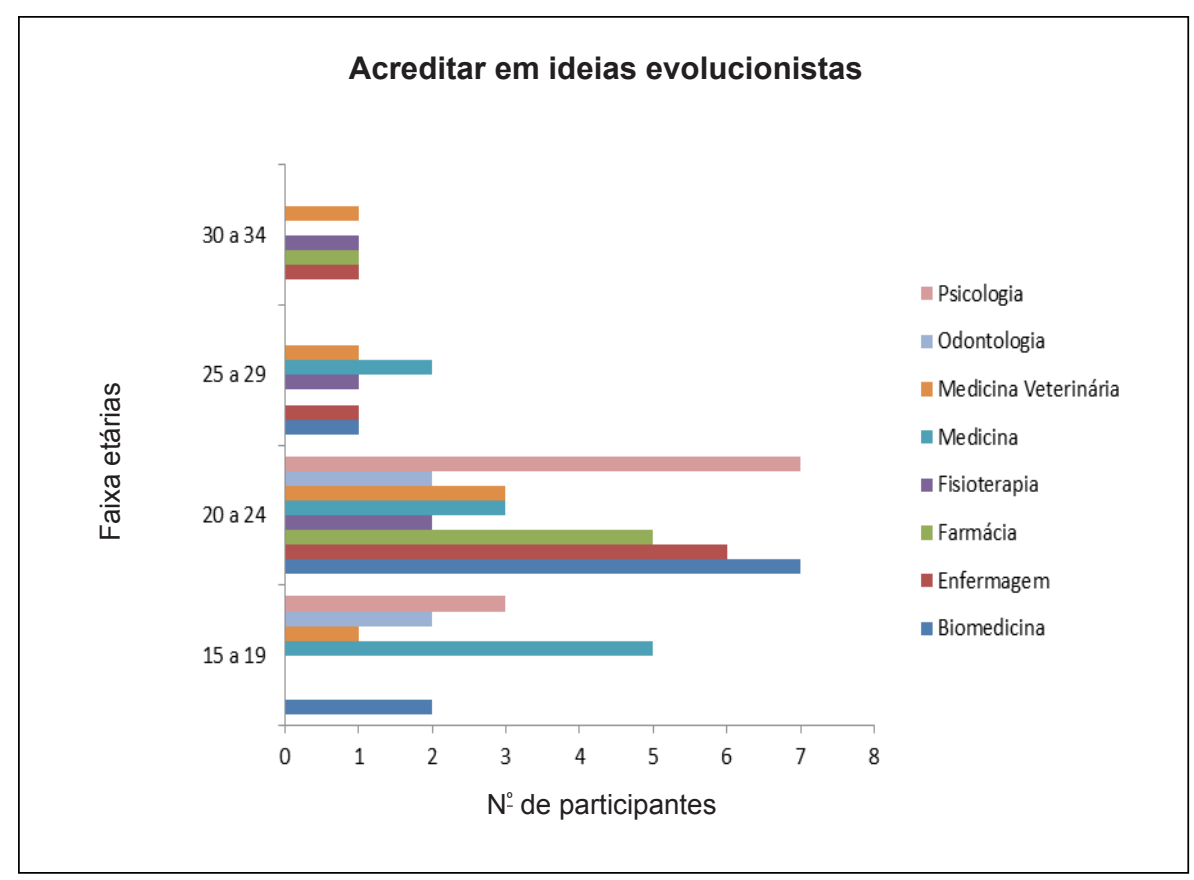

Figura 3. Número de estudantes, entre os entrevistados, por faixa etária, que acreditam em ideias evolucionistas, de acordo com Darwin, do Centro de Ciências da Saúde, da Universidade Severino Sombra. 


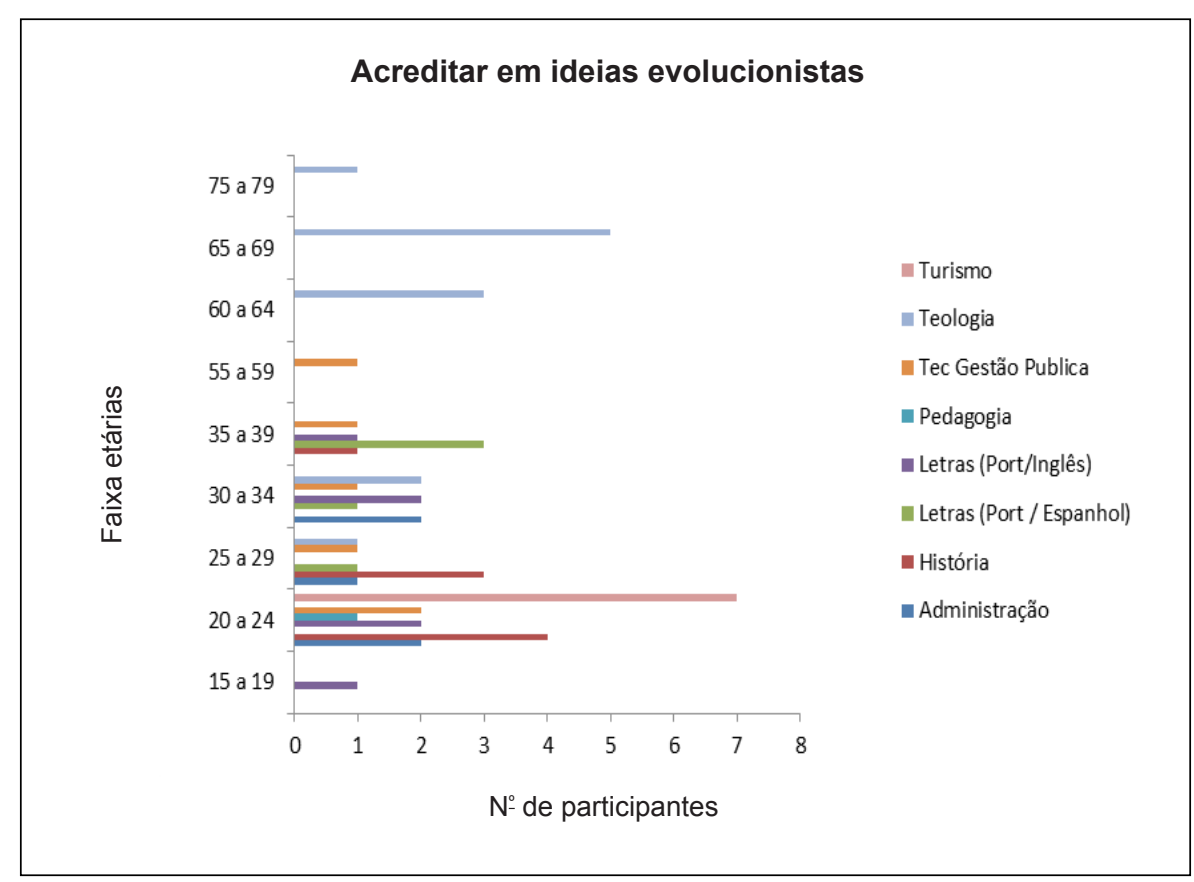

Figura 4. Número de de estudantes, entre os entrevistados, por faixa etária, que acreditam em ideias evolucionistas, de acordo com Darwin, do Centro de Ciências Sociais, Aplicadas e Humanas, da Universidade Severino Sombra.

Os resultados para as demais faixas etárias diversificam em função da idade predominante na população estudantil por área de conhecimento. Nos cursos da área da Saúde registrase uma população mais jovem, entre 14 a 24 anos; nos cursos da área humana, na faixa etária entre 20 a 24 anos encontra-se 40,0\% da população e os demais, 60,0\%, encontramse distribuídos nas demais faixas, com prevalência entre 20 a 39 anos e entre 60 a 69 anos; nos cursos da área de exatas e tecnológicas, na faixa entre 20 a 24, encontra-se 48,72\% da população, com predominância para a faixa etária entre 15 a 34 anos.

Entre os alunos dos cursos da área de Exatas e Tecnológicas, participantes da pesquisa, com predominância da faixa etária de 20 a 24 anos (48,72\%) e de 25 a 29 anos (23,08\%), foram registrados os maiores índices para acreditar em idéias evolucionistas nos cursos de Ciências Biológicas 92,0\%, Técnico em Gestão de Agronegócios 87,5\% e Química Industrial $80,0 \%$.

Comparando os cursos da área do conhecimento de Humanas, verificou-se entre os estudantes de Teologia, com predominância de faixa etária mais alta, 60 a 79 anos, um maior percentual em acreditar em idéias evolucionistas. Entre os alunos representantes do curso de Turismo, 87,5\%, na faixa etária entre 20 a 24 anos, responderam "sim" para a questão de estudo.

O mesmo estudo realizado na área da Saúde demonstrou uma população predominante na faixa etária entre 15 a 24 anos, onde 100,0 \% dos representantes dos cursos de Biomedicina, Medicina e Psicologia acreditam em ideias evolucionistas. 
Distribuídos entre todas as faixas etárias e áreas do conhecimento encontrou-se alunos que não acreditam em idéias evolucionistas: $24,7 \%$ entre os participantes da área da saúde, $23,2 \%$ da área de humanas e $22,0 \%$ da área de ciência, tecnologia e natureza.

\section{Considerações}

Não se pode esperar da Teoria da Evolução de Darwin resposta a todos os problemas que levantou, encontrando-se limitada pelas próprias condições de produção no século XIX, nem mesmo com as contribuições das pesquisas contemporâneas.

O debate sobre o evolucionismo não se restringe a ocorrer entre ateus e crentes; entre fé e razão; mas entre os cientistas, pois se discute se a teoria da evolução é uma ciência verdadeira. O darwinismo pode ser entendido como parte de uma "visão do mundo". O pensamento evolucionista de Darwin não era uma simples hipótese científica formulada para combater idéias religiosas; sofreu influência da revolução industrial e das revoluções políticas, principalmente da Revolução Francesa, acontecimentos históricos desenrolados entre os anos 1776 e 1848 (Howard E. Gruber, como citado por Pinheiro, 2000, p.2).

Em virtude dos poucos dados encontrados na literatura e a pesquisa não envolver as tendências religiosas dos participantes, os resultados deste estudo demonstram um maior índice, 23,3\%, de não aceitação das ideias evolucionistas em relação àqueles realizados por Souza, Carvalho, Matsuo e Zaia (2009, p.40), onde "8,9\% dos entrevistados não aceitam a teoria evolutiva e acreditam na versão da Bíblia para a criação". Nos dois estudos encontrou-se, pelos dados obtidos, principalmente no curso de Teologia, que "a grande maioria dos entrevistados não vê conflito entre evolucionismo e religião." Este posicionamento leva ao questionamento se o evolucionismo então considerado seria a evolução biológica ou a evolução humana em seus aspectos filosóficos.

$\mathrm{O}$ acreditar em ideias evolucionistas, predominante na faixa etária entre 20 a 24 anos, na maioria dos cursos, e na idade madura no curso de Teologia, não permite avaliar se estes posicionamentos são independentes da divulgação ou do ensino do criacionismo introduzido há algum tempo nas escolas públicas de alguns estados brasileiros. De qualquer forma, pode-se inferir a partir deste estudo um grande desconhecimento sobre a teoria científica evolucionista.

Uma das ideias que se acrescentou à discussão sobre acreditar no evolucionismo encontra-se no Desenho Inteligente do biólogo Michael Behe (1997) que argumenta que o evolucionismo não explica todas as apomorfias morfológicas e muito menos apomorfias das estruturas moleculares, principalmente através de modificações ao longo do tempo. Este movimento neo-criacionista, com argumentos científicos, tem conseguido adeptos principalmente nas Américas, mas ao que tudo indica ainda não chegou aos estudantes pesquisados.

Evidencia-se a premência de levar aos estudantes, a apreensão do pensamento da Biologia e especialmente da Evolução, como processo dinâmico, não estático, característicos e inerentes à vida. 
Numa visão holística das ciências e do homem, para pensar o homem como um ser completo, integrante do Universo, há necessidade de superar os limites da biogenética, da neurologia, da paleontologia, da etnologia, da antropologia, da psicologia e de outras ciências. A redescoberta do homem completo, na visão do ser humano defendida por Vigotski (1997) e Vigotski e Luria (1991, como citados por Pino, 2009,p. 863), fazse no sentido de que emergindo no fluxo evolutivo da vida, de um longo e ancestral passado biológico, ascendeu na escala animal, fazendo das funções biológicas herdadas o suporte das novas funções culturais e simbólicas que construiu e continua construindo no confronto com a natureza da qual faz parte. A todas as ciências cabe a construção da imagem humana do homem (Pino, 2009, p.863).

Acreditar no mundo e na vida com base em argumentos evolucionistas permite e permitirá ao homem entender a necessidade de buscar diferentes funções e habilidades, além de entender o significado das mudanças e das diversidades que serão capazes de levá-lo a sobreviver a si mesmo, pois

[ ] diferentemente dos outros seres vivos, participa de sua trajetória evolutiva [ ] tenta penetrar, ao mesmo tempo, nos espaços siderais mais distantes do universo e nas profundidades moleculares da vida para desvendar seus mistérios. O surpreendente é o pouco que ele ainda sabe de si mesmo, dessa sua condição humana de ser que vem construindo sem prestar suficiente atenção a isso e cuja ignorância pode até comprometer sua promissora caminhada de progresso (Pino, 2009, p.848). 


\section{Referências}

Behe, M. J. (1997) A Caixa Preta de Darwin. Rio de Janeiro: Jorge Zahar.

Castaneda, L. A. História natural e as idéias de geração e herança no século XVIII: Buffon e Bonnet. Hist. cienc. saude-Manguinhos [online]. 1995, vol.2, n. ${ }^{\circ}$ 2, pp. 33-50. ISSN 0104-5970. Recuperado em 20 novembro de 2009 de http://www.scielo.br/pdf/hcsm/ v2n2/a03v2n2.pdf

Fedeli, O.; Vanini, F.; Vanini, M. M.; Oliveira, D. A. (2003). Evolucionismo: dogma cientifico ou tese teosófica? Associação Cultural Montfort. Recuperado em 16 março de 2011 de http://www.montfort.org.br

Ferreira, M. A. (2007). Transformismo e Extinção: de Lamarck a Darwin. Tese de Doutorado, Universidade de São Paulo, São Paulo, SP. Recuperado em 20 de março de 2011 de http://www.diaadiaeducacao.pr.gov.br/diaadia/diadia/arquivos/File/ conteudo/ artigos_teses/2010/Biologia/teses/lamarck_darwin.pdf.

Maia, H. L. S. (2004) Criacionismo vs. Evolucionismo Other Titles: da ciência e da cultura Porto: Edições Universidade Fernando Pessoa. CTEC ConsCiências: actas do Fórum Internacional Ciência, Religião e Consciência. ISSN 1645-6564. 2 (2005) 363-368. Recuperado em 11 junho 2009 de http://ufpbdigital.ufp.pt/dspace/ bitstream/10284/784/3/363-368Cons-Ciencias\% 2002 -11.pdf

Pino, A. (2009) Ciência e educação: a propósito do bicentenário do nascimento de Charles Darwin. Revista Ciência e Educação, Vol.30, n. ${ }^{\circ} 108$. Recuperado em 15 de março de 2012 de endereço: http://scielo.br/pdf/es/v30n108/a1130108.pdf

Pinheiro, A.(2000). Evolucionismo: mais do que teoria cientifica, um sistema metafísico. Ciência e Fé. Morfort. Recuperado em 15 fevereiro de 2012 de http://www.montfort. org.br

Souza, R.F., Carvalho, M., Matsuo, T. e Zaia, D. A.M. (2009). Evolucionismo x Criacionismo: aceitação e rejeição no século 21. Revista Ciencia Hoje Rio de Janeiro: SBPC, V.43, n. ${ }^{\circ} 256$, pág 36-41.

Teilhard de Chardin. P. (1955). Le phénomene humain. Paris: Éditions du Seuil.Recuperado em 21 novembro de 2009 de www.ubest1.com/ebook/GNU_Reader_1309471722.pdf 